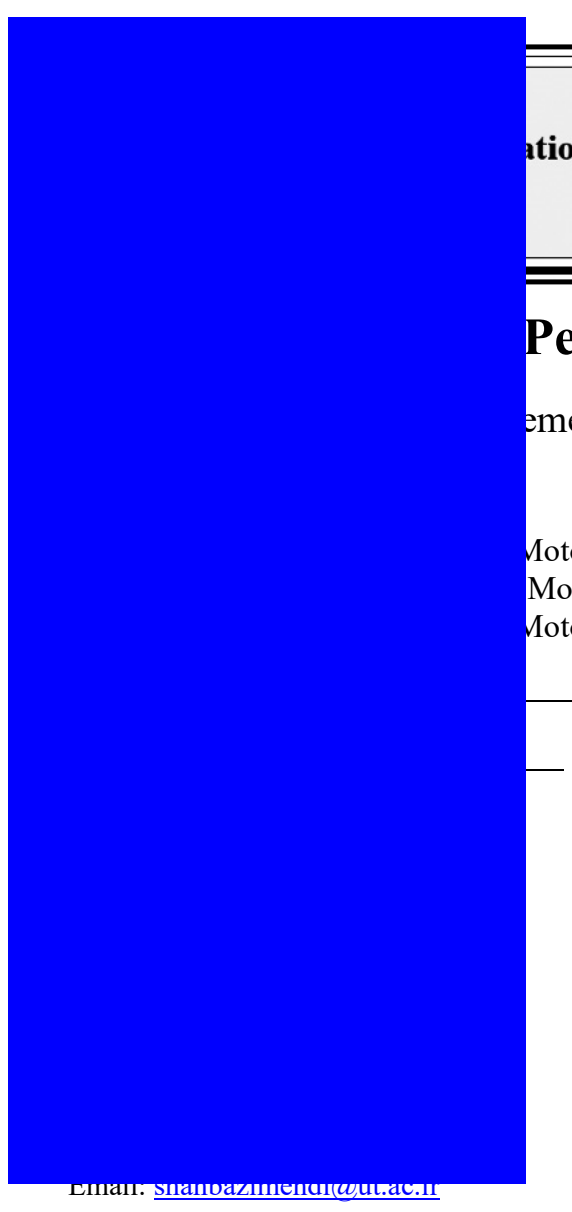

Received: 2019/04/08

Accepted: 2019/07/07

Published: 2019/08/23
Contents Lists is Available Online

tional Journal of Motor Control and Learning (IJMCL)

Journal Homepage: www.ijmcl.com

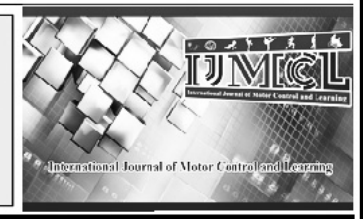

\section{Performance due to Exercise Intensity and Arousal}

emeh Rezaei ${ }^{a}$, Mehdi Shahbazi ${ }^{b *}$, Bahram Ghafari $^{c}$

Motor Behavior, University of Tehran, Iran

Motor Learning and Control, Faculty of Sport Sciences, University of Tehran, Tehran, Iran

Motor Behavior, University of Tehran, Iran

\begin{abstract}
Objective: The aim of this study is to investigate the effect different levels of exercise intensity and arousal has on the speed and the accuracy of decision making among expert female soccer players.
\end{abstract}

Methods: Sixteen expert female soccer players with at least 8 years competitive background were selected voluntarily participate in this study. Soccer experiment images were displayed on a screen where the participants had to choose a response from three options (shoot, pass, and dribble) in order to assess the decision making performance. The test experiments were designed in three arousal and three exercise intensity levels. In order to examine any significant effect of the levels of different situations, a One-Way ANOVA with Repeated Measures was performed to find the effects of mentioned variables on the accuracy and the speed of decision making. Results: The results obtained from the present study did not reveal any significant effect of level of arousal on the speed of decision making ( $p>0.05$ ). The accuracy of decision making, however, was significantly affected by the exercise intensity $(\mathrm{p}<0.05)$. With increasing the exercise intensity, the players' speed of decision making showed an improvement with no spectators and the presence of inactive spectators at different levels of arousal. It was only at the exercise intensity level of $80 \%$ max HR that the best accuracy of decision making was observed at the presence of inactive spectators.

Conclusion: The present findings suggest that the level of arousal and the exercise intensity affect each of decision-making components separately. 


\section{Introduction}

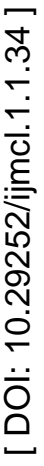

which is a live field of research for psychologists and neurologists. A key part of expert performance in many fields, such as sport, law enforcement or medicine, is successful decision-making. Decisionmaking is defined as the ability to use information from the current situation and the knowledge possessed about it so as to plan, select and execute an appropriate goal-directed action or set of actions (Willams \& Ford, 2013). The fundamental question that directs decision making investigations towards this area is to find out why different people encountered by similar experiments make different decisions. What are the cognitive and neuropsychological processes that result in different responses from individuals? According to Classical Decision Theory, decision making includes choosing a series of activities from a certain level of options with having a specific goal in mind. The three components of decision include: a) options or series of activities, b) ideas and expectations from options for reaching the goal and c) result expectations (positive or negative). According to this theory the goal of decision making is to optimize the achievements or result expectations and utilizing information in an order to achieve the mentioned goal (Gutnik et al., 2006). Proper use of cognitive skills such as visual search, pattern recognition, estimation of probable experiments and prediction for efficient decision making are among important activities in professional sports (Williams, Davids, \& Williams, 1999). The importance of expert performance, suggests an increasing focus of investigations to be put on the prediction and understanding of decision making in sports. Many of the studies on cognitive tasks have shown that elite players have optimal performance in decision making as compared to amateur/inexperienced players (Mann et al., 2007). Not only the performance but also resources (for example specialized knowledge as opposed to general knowledge) is different in performance when comparing elite and inexperienced individuals (Zoudji, Thon, \& Debu, 2010).

Roca and Williams (2017) highlighted that the There appears to be some positive transfer of decision-making between sports that share similar elements, supporting the importance both of specificity and generality in expert performance. They argued that the ability to make decisions 26 under time pressure is crucial to performance in 
sport. However, there remains a paucity of research that examines whether the skills underpinning decision-making transfer across similar or dissimilar sports. They examined whether decision making transfers from soccer to other sports that may be deemed to be either similar (basketball) or dissimilar (tennis) based on sports taxonomy. Skilled soccer players $(N=20)$ completed a videobased temporal occlusion test designed to measure decision-making involving offensive sequences of play from soccer, basketball, and tennis. Participants were required to decide on an appropriate action to execute for each situation presented. Response accuracy was higher in the soccer decision-making task compared to the basketball and tennis tasks. Furthermore, accuracy scores were higher on the basketball compared to the tennis task (Roca \& Williams, 2017).

The experiments therefore, have been designed and conducted with the goal of clarifying the role of specialization on decision making and motor skills in order to find out if expert players possess superior and quicker decision making and performance (Campos, 1993; McPherson, 1999). The fact that experts' superiority in performance is known however, there is little known about the aspects of information processing, its components, primary information, memory, decision making and performing motor skills _ and that if they are achieved through practice. Considering the essential role of decision making in open loop skills, many of the explanatory literature correlated specialization and decision making. It is shown that expert players make quicker and more accurate decisions as compared to novices (Ripoll et al., 1995; Kioumourtzoglou et al., 1998; McPherson, 1999; Nielsen \& McPherson, 2001; campos, 1993; McMorris, \& Beazeley, 1997). Manstesd and Semin comprehended the capacity model from two procedure information processing models by Shifftin and Schneider. Instead of dividing tasks into simple and complicated, they conducted an exact division on tasks which required controlled cognitive information versus tasks that required automatic cognitive information. Automatic tasks were performed superiorly when processed at the presence of others. This phenomenon is predictable in capacity theory. Therefore, automatic tasks tend to drop the quality of performance at the lack of other's presence. The presence of others does not initiate focus on self-performance and capacity limitation in the short-term memory and therefore the performance improves. When performing tasks that required controlled cognitive processing and more attention capacity, the presence of spectators is a factor requiring more attention concurrently. Therefore because of the limited capacity of the controlled process, performance quality of such 
tasks decreases at the presence of others (Cox, 2000). The experiments conducted on this aspect constantly indicate soccer as an important tool for examining decision making in sports (McMorris \& Graydon, 1996, 1996a, 1997b; McMorris et al., 1999). Soccer is an open loop sport, defined by several concurrent tasks taking place. In fact, even the players who are not playing with the ball perform a variety of skills. Running and locating in accordance with the teammates and opponents are some of these tasks. Examples of the tasks performed when a player is in possession are controlling the ball, passing the ball, dribbling or shooting. Having several tasks to perform, there are a relatively high number of potential options and there are several decisions a player should make during the game. A player in possession for instance, should decide whether he /she is going to pass the ball to a teammate, dribble an opponent, run forward with it, make a shot to the goal or perform some different task. There are several options for each given decision available as well. When passing the ball to a teammate for instance, one should decide to which one of his/her teammates to pass the ball to and which passing technique will be appropriate for the current experiment. Having many options, expert players normally make accurate and quick decisions. Like other open loop sports, speed and accuracy of the decisions in soccer are often measured through decision making experiments. There are two goals for examining the speed and accuracy in decision making: The first goal is that since both qualifications in decision making are essential for the dynamics of the game, the player requires making quick and accurate decisions based on the information that his/her current experiment provides. Quick decision making does not mean missing the opportunity of creating a good situation play nor it means losing the ball, rather, usually failing to make quick decisions means missing the opportunity for performing the optimal skill for a given experiment. The other goal depends on the emphasis of the players on the speed of the accuracy of the decision. If the participant is told the time factor of decision making task is not of importance, he/she might merely allocate attention to the accuracy. In such case the difference between an expert and novice player is eliminated (Fontana, 2007).

McMorris and Greydon's studies (1996 a, b \& 1997 a \& b) investigated the effects of practice on performing similar to participants' tasks. They studied the effects of the intensity of practicing at $70 \%$ and $100 \%$ power out-put on the performance of soccer players in decision making tests at different competition levels. The results from comparing the performance at rest and 100\% 
power out-put revealed that the speed of decision making was significantly higher under $100 \%$ power out-put and practicing had no significant effects on the accuracy of decision making. The results showed that the speed of decision making during practice at $70 \%$ power out-put was the same at different conditions. In all three investigations the speed of decision making at $70 \%$ of power output was significantly faster than resting, however, there was not such a significant difference reported in other studies. There was only been a significant difference between $70 \%$ power out-put and maximum power out-put reported in one investigation. McMorris and Graydon (1997b) justified the results of the accuracy of decision making with kahnmman's Multi-dimensional allocation of recourses theory (1973). According to Kahnman's theory arousal holds two dimensions; effort and arousal. Arousal indicated the resources available to the CNS while effort is responsible for allocating this source. Other scientists also presented other theories following the above mentioned (Pribram \& McGuinness, 1975; Sanders, 1983, Humphreys \& Revelle, 1984). According to McMorris and Graydon's theory as long as, similar to the tests, the task is familiar for the individual there is an automatic component and few sources from CNS will be required for optimal performance. Therefore, even if the available resources are few, such as at resting, effort can allocate enough resources in order to secure the accuracy of performance. This justifies the lack of significant difference between the accuracy of performance in $70 \%$ and maximum power out-put levels. The allocation of resources theory justifies the decrease in the accuracy of performance in $100 \%$ power output as compared to $70 \%$ power out-put. McMorris and Graydon (1997b) predicted that their results supports Izank (1992)'s reasoning which indicates that effort for allocating resources to the task is possible even in less than maximum arousal levels. Results from the speed of decision making are not easily justified by allocation of resources' theory. McMorris and Graydon (1997b) argued that increasing the speed of decision making in maximum practice is due to the increase in arousal which leads into increasing the available resources from the CNS. If the effort guarantees the focus of attention on the task and there are more resources available as compared to resting level an increase in the speed of decision making will be inevitable. Investigations on the effect of accumulating practice on the catecholamine density levels of the plasma showed that adrenaline and nor-adrenaline increase concurrently during such exercises (Podolin et al., 1991; Schneider et al., 1992; Hughson et al., 1995). The densities during maximum training are significantly higher 
than resting level. The important to note is the spots where adrenaline and nor-adrenaline show a significant increase compared to the base density levels. These levels are called threshold levels of adrenaline and noradrenaline respectively (Lehman et al. 1981). There has been a huge difference between this two group's average in oxygen consumption and power output. More important than that there has been a huge individual difference reported from these groups (Flanagan et al., 1991; Schneider at al., 1992; Urhausen et al., 1994). Therefore the lack of significant increase in the speed of decision making is not unpredictable from McMorris and graydon (1996 a, b, 1997 a, b) participants in the case some of them have not passed their threshold. In mcMorris, Steve Myers at al. (1999) on "exercise, plasma catecholamine density and decision making among college soccer players" they compared college soccer players decision making performance at resting, adrenaline threshold and maximum power output. The main goal for the mentioned study was to compare the decision making performance among college soccer players. This test included tachistoscopically test at resting, during practice that adrenaline levels are at threshold and at maximum power output. Exhaustion test was performed on an ergo meter bike. After maximum power output test the 9 participants of the study were to take 10 soccer decision making efforts. Their decision making performance was assessed at resting, at their adrenaline levels being at threshold during paddling (tested from before) and during maximum power output. The accuracy and the speed of decision making was the dependent component. One Way MANOVA revealed no significant effects of adrenaline levels with the accuracy of training. There was a significant relation between the speed of decision making and the intensity of exercise. Tukey's HSD tests revealed that the speed of decision making at resting level is significantly lower than the two other situations. The two other situations were not significantly different. According to arousal and performance theoretical resources adrenaline levels cause an increase in the available resources among individuals. Training at maximum power output, only results in arousal at a moderate level and not a high level (McMorris et al., 1990).

Saha et al. (2014) in their paper suggested contribution of other psychobiological aspects on emotional resilience revealed that, soccer players having faster orienting recovery; relatively lower amplitude and comparatively delayed latency had higher extent of emotional resilience. Tolerance indices however revealed that as high as $70.6 \%$ of extent of amplitude and $73.4 \%$ of latency were not 
predicted by other apparently corroborated autonomic variables. Thus overall impression implied that, soccer players having faster recovery; lower extent of amplitude and relatively delayed latency would have better emotional resilience [35] (Saha et al., 2014).

Zoudji and his colleagues' (2010) study presented the latest decision making tool related to various situations in soccer. Accessing this tool is the biggest step in order to begin an investigation on the field of decision making. Among the decision making tools available for soccer situations McMorris and graydon's (1997) and Fontana's review article (1997) could be mentioned. In the field of sports, information processing and decision making, experiments on differences between expert and the novice has investigated basketball players (Brad \& Fleury, 1976; Yaaron et al., 1997), water polo players (Kioumourtzoglou et al., 1998), handball players (Tennenbaum et al., 1993), soccer players (McMorris \& graydon, 1997; Fontana, 2007), and boxers (Lopez et al., 2008), and memory and decision making functions in expert and novice (Zoudji \& Thon, 2003 \& Zoudji et al., 2010). The results obtained from the mentioned studies revealed that level of expertise has a significant effect not only on performance but also on resources (specialized knowledge versus general knowledge) and performance related processing (automatic versus controlled). When it comes to decision making, experts' performance takes place relying on automatic processes that are based on specialized knowledge obtained through experience (Zoudji et al., 2010). Larkin et.al (2016) conducted a study on the influence of grit on sportspecific engagement and perceptual-cognitive expertise in elite youth soccer. Their findings revealed that grittier players accumulated significantly more time in sport-specific activities including competition, training, play, and indirect involvement. Moreover, there was a significant main effect for performance on the perceptualcognitive skills tests across groups, with grittier players performing better than less gritty players on the assessments of decision making and situational probability. In soccer, Marriott, Reilly \& Miles (1993) and Tennenbaum et al. (1993) have examined the accuracy and decision making. McMorrsi and Graydon (1996) and Fontana (2007) examined the accuracy and speed of decision making. The results obtained from the mentioned studies suggest that moderate exercise intensity is the best experiment for assessing the accuracy of decision making. One exception is Fontana's experiment (2007) in which the author does not mention the intensity of exercise as an effective variable. The latter study suggest moderate to high 
and high are the best exercise intensity to assess performance among expert and novice players.

In sport sciences, the model of decision making is originally designed to focus on recognizing competitions (Raab, 2003). Recognizing the competition in games is concentrated on qualitative and quantitative analysis of offensive and defensive behaviours (Perl, 1997). Minimal efforts have been made in order to change the mechanisms of decision making (Alain \& Sarrazin, 1990; Andreas, 1996; Sarrazin, Alain, \& Lacombe, 1986). A review on the internal investigations on motor control and information processing we recognize that not much has been done on the aspect of decision making in sports. Despite the importance of decision making in ball sports, due to the issues related to control in these types of studies and lack of proper tools and methods for carrying these studies out. there has been few studies done regarding them.

Manipulating arousal levels in laboratory experiments has shown that this variable has a significant effect on cognitive performance even in a constant level of intensity (Shmidt et al., 2004). In the present study therefore, we implemented a process protocol compatible to a soccer match (for instance the intensity of exercise and the level of arousal) under which the accuracy and the speed of decision making in expert soccer players were examined. The results are dedicated to anyone interested in this field of investigation.

\section{Method}

The present study is a quasi-experimental investigation.

\section{Statistical Population and the Sample}

The sample for this study was recruited based on Cochran's sample size formula and at $95 \%$ significance level. The sample consists of 16 female expert soccer players with the background of at least 8 years of participation in soccer competitions. The sample was randomly drawn from amongst Tehran provincial clubs team members who voluntarily participated in this study.

The present study was conducted at two separate parts of physical fitness and decision making test. All of the stages of the experiment were conducted in the physiology laboratory of the faculty of Physical Education and Sports Science, University of Tehran. In the first stage of the experiment in order to reach to their maximum heart rate all of the participants went under a fit test using Bruce and Borg RPE scale. Participants continued running/walking until they were exhausted and unable to go on. The Target Heart Rate was calculated based on Karvonen method using participant's resting heart rate and the heart rate obtained from the Bruce Test. The calculated heart 
rate from each participant was separately written on the results sheet separately.

$$
\begin{gathered}
\mathrm{THRx}=\mathrm{HR}_{\text {rest }}+\mathrm{x}\left(\mathrm{HR}_{\max }-\mathrm{HR}_{\text {rest }}\right) \\
\{\text { Karvonen Formula }\}
\end{gathered}
$$

The decision making experiments at different exercise intensities and arousal situations were conducted after the fit tests were done. Testing experiments were HR rest - No Spectators, 40\% HR max - No Spectators, 80\% HR max - No Spectators, HR rest-Inactive Spectators, 40\% HR max - Inactive Spectators, $80 \%$ HR max - Inactive Spectators, HR rest-Active Spectators, 40\% HR max - Active Spectators, 80\% HR max - Active Spectators. Each participant was asked to choose the best action for the player in possession displayed in the image as quick and accurate as possible. The decision making tool included soccer situation pictures all taken in similar conditions; 2 meters above the ground, 3 meters in front of the gate, all $11 \mathrm{~cm}$ length and $15 \mathrm{~cm}$ width with a zerodegree angle spot vision when observed on the computer screen. All defence players plus the goal keeper wearing red and all offense players wearing yellow. The response time is recorded at one millisecond taken place right after the picture is displayed. Each picture has only one correct answer. For each of the 9 situations of the test 20 pictures including ten $2 \times 2$ and ten $2 \times 3$ picked randomly using random numbers chart. Once the participants were located on the treadmill at the desired situation the pictures were displayed one after another upon pushing the start button in the form of slides. The lap top computer was located on the treadmill at $50 \mathrm{~cm}$ from the participant. The 14 " screen displayed all other images at the same resolution. According to the descriptions each participant chose the best action for the player who possessed the ball as quick and accurate as possible.

\section{Statistical Procedure}

Descriptive data was used on order to describe the investigation's variables. The data were approved to be normally distributed using the $\mathrm{K}-\mathrm{S}$ test and variances' homogeneity using the Leven's test. In the nest step and in order to examine if there are any significance differences between the test situations a one-way repeated measures ANOVA followed by Tukey's HSD post hoc in case of any significant results at 95\% significance level was performed on the data. The data obtained from the participants were analysed using SPSS 16 application. The data was input to the application separately for the reaction time (the speed of decision making) and correct answers (the accuracy of decision making). 


\section{Results}

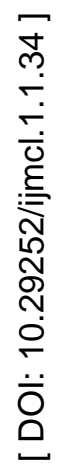

Table 1. Descriptive analysis of demographic characteristics of the participants of the study.

\begin{tabular}{|c|c|c|c|}
\hline & $\begin{array}{c}\text { Standard } \\
\text { Deviation } \\
\text { /Average }\end{array}$ & $\begin{array}{c}\text { The } \\
\text { Smallest }\end{array}$ & $\begin{array}{c}\text { The } \\
\text { Largest }\end{array}$ \\
\hline $\begin{array}{c}\text { Age } \\
\text { (yrs) }\end{array}$ & $23.4 / 3.8$ & 18 & 29 \\
\hline $\begin{array}{c}\text { Height } \\
\text { (cm) }\end{array}$ & $161 / 5.9$ & 170 & 152 \\
\hline $\begin{array}{c}\text { Weight } \\
\text { (kg) }\end{array}$ & $57 / 8$ & 46 & 67 \\
\hline $\begin{array}{c}\text { Sports } \\
\text { Background } \\
\text { (yrs) }\end{array}$ & $9.43 / 1.9$ & 8 & 13 \\
\hline
\end{tabular}

The results from the speed and the accuracy of decision making of the participants in different arousal situations (with no spectators, inactive spectators and active spectators) is shown in table 2.

Table 2. The difference between the speed and the accuracy of decision making in different levels of arousal.

\begin{tabular}{|c|c|c|c|}
\hline Main Factor & $\begin{array}{c}\text { Degrees of } \\
\text { freedom }\end{array}$ & F & Significance \\
\hline $\begin{array}{c}\text { The Speed of Decision } \\
\text { Making at Different Levels } \\
\text { of Arousal }\end{array}$ & 2 & 0.601 & 0.550 \\
\hline $\begin{array}{c}\text { The Accuracy of Decision } \\
\text { Making at Different Levels } \\
\text { of Arousal }\end{array}$ & 2 & 12.535 & $0.000 *$ \\
\hline $\begin{array}{c}\text { *Significance at } p<0.05 \\
\text { pisice } p\end{array}$ & & \\
\hline
\end{tabular}

The results from the Analysis of Variance revealed that the average decision making response time was not significantly affected by the level of arousal. There was a significant effect of level of arousal in the accuracy of decisions made $(\mathrm{P}<.05)$. Contrasts revealed there is a significant difference between the accuracy of decision making at low level of arousal and moderate level of arousal $(\mathrm{p}<.05)$. There also is a significant difference between the accuracy of decision making at moderate and high levels of arousal $(p<.05)$. There is however, no significant difference of accuracy in decision making at low and high levels of arousal $(\mathrm{p}<.05)$.

Table 3. The Accuracy and speed of decision making at different levels of arousal.

\begin{tabular}{|c|c|c|c|}
\hline Variable & $\begin{array}{c}\text { Degrees of } \\
\text { Freedom }\end{array}$ & F statistic & $\boldsymbol{\alpha}$ level \\
\hline $\begin{array}{c}\text { Accuracy at different } \\
\text { levels of arousal }\end{array}$ & 2 & .601 & .550 \\
\hline $\begin{array}{c}\text { Accuracy at different } \\
\text { levels of Arousal }\end{array}$ & 2 & 12.535 & $.000^{*}$ \\
\hline
\end{tabular}

\section{Speed and accuracy of decision making at different levels of arousal}

The findings of the present study in correspondence to the different levels of arousal have been shown in table 3. According to table 3, the speed of decision making at a low level of arousal (HR resting, $40 \% \mathrm{HR} \max$ and $80 \%$ of $\mathrm{HR} \max$ ) is significantly affected by the level of exercise intensity. The pace at which participant respond decreases with increasing the level of exercise intensity from resting to $80 \% \mathrm{HR}$ max. The accuracy of decision making among expert players shows a score approximately equal to 10 at all levels of exercise intensity.

At a moderate level of arousal, the speed of decision making decreases from HR resting to $80 \%$ 
HR max, though it is not significant. Increasing the level of exercise intensity only has a significant effect at $80 \%$ HR max on the accuracy of decision making $(\mathrm{P}<0.05)$. In other words participants' accuracy of decision making was not significantly affected by the intensity of the exercise except for in high intensity exercise.
According to table 4, the speed of decision making is slightly different among expert soccer players at a high level of arousal. The average response time was slower at resting HR compared to the other two conditions. Increasing the level of exercise intensity at high levels of arousal does not have a significant effect on the accuracy of decision making among expert soccer players $(\mathrm{P}<0.05)$.

Table 4. The Speed and the Accuracy of Decision Making at Different Levels of Arousal and Exercise Intensity.

\begin{tabular}{|l|c|c|c|c|c|c|}
\hline & \multicolumn{3}{|c|}{ Average Error } & \multicolumn{3}{c|}{ Sig } \\
\hline & $\begin{array}{c}\text { Low } \\
\text { intensity }\end{array}$ & $\begin{array}{c}\text { Moderate } \\
\text { Intensity }\end{array}$ & $\begin{array}{c}\text { High } \\
\text { Intensity }\end{array}$ & $\begin{array}{c}\text { Low to } \\
\text { Moderate }\end{array}$ & $\begin{array}{c}\text { Low to } \\
\text { High }\end{array}$ & $\begin{array}{c}\text { Moderate } \\
\text { to High }\end{array}$ \\
\hline Speed at low level of Arousal & $2.97 \pm 0.2$ & $1.92 \pm 0.1$ & $1.56 \pm 0.1$ & $* * 0.000$ & $* * 0.000$ & 0.271 \\
\hline Accuracy at low level of Arousal & $10.14 \pm 0.8$ & $10 \pm 0.9$ & $10.43 \pm 06$ & 0.7 & 0.797 & 0.898 \\
\hline Speed at moderate level of Arousal & $2.22 \pm 0.08$ & $2.08 \pm 0.07$ & $1.76 \pm 0.07$ & 0.012 & $* * 0.000$ & 0.393 \\
\hline Accuracy at moderate level of Arousal & $11.93 \pm 0.6$ & $11.57 \pm 0.5$ & $14.5 \pm 0.7$ & $* * 0.001$ & $* * 0.004$ & 0.141 \\
\hline Speed at high level of Arousal & $2.2 \pm 0.1$ & $2 \pm 0.1$ & $2.03 \pm 0.1$ & 0.965 & 0.224 & 0.141 \\
\hline Accuracy at high level of Arousal & $10 \pm 0.5$ & $10.71 \pm 0.8$ & $9.5 \pm 0.8$ & 0.217 & 0.580 & 0.490 \\
\hline
\end{tabular}

\section{The speed and the accuracy of decision making at different levels of exercise intensity}

This part of the findings of the present study has been shown in figures 1 and 2. Figure 1 displays a block diagram of average speed of decision making among expert soccer players in different arousal and exercise intensity levels. The findings have been categorized by the level of the intensity. According to the diagram, on average players have the quickest decision making at HR resting exercise intensity. Speed of response is not significantly different at different levels of arousal. This variable significantly deteriorates with increasing the level of exercise intensity. 


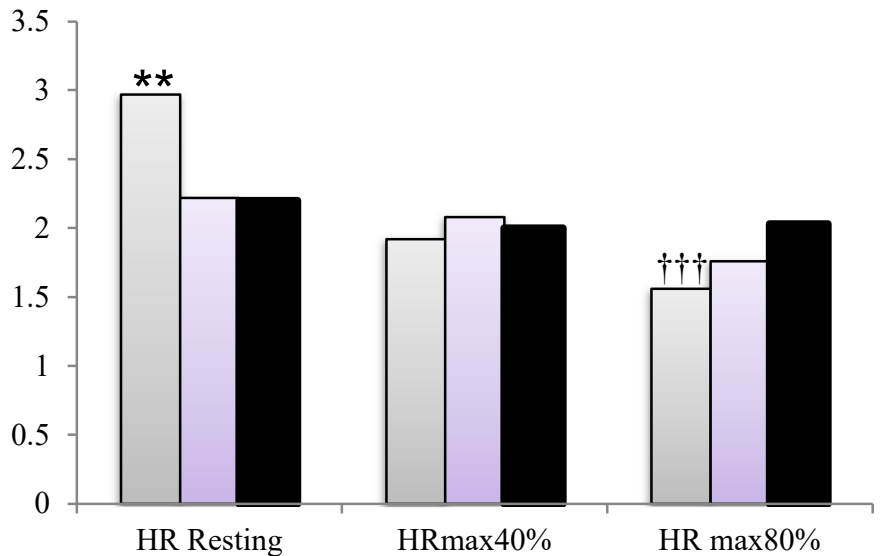

$\square$ Low Arousal

$\square$ Moderate Arousal

Digh Arousal

Figure 1. Block diagram comparing the speed of decision making at different levels of exercise intensity and arousal. The sign $* *$ indicates a significant difference between no spectators and the two other conditions at the exercise intensity of $\mathrm{HR}_{\text {resting }}(P<.01)$. The sign $\uparrow \dagger \uparrow$ indicates a significant difference between low arousal (no spectators) and high arousal (active spectators) condition at exercise intensity level of $80 \% \mathrm{HR} \max (\mathrm{P}<0.001)$. The data displayed: mean \pm SD and No. Of participants $=16$.

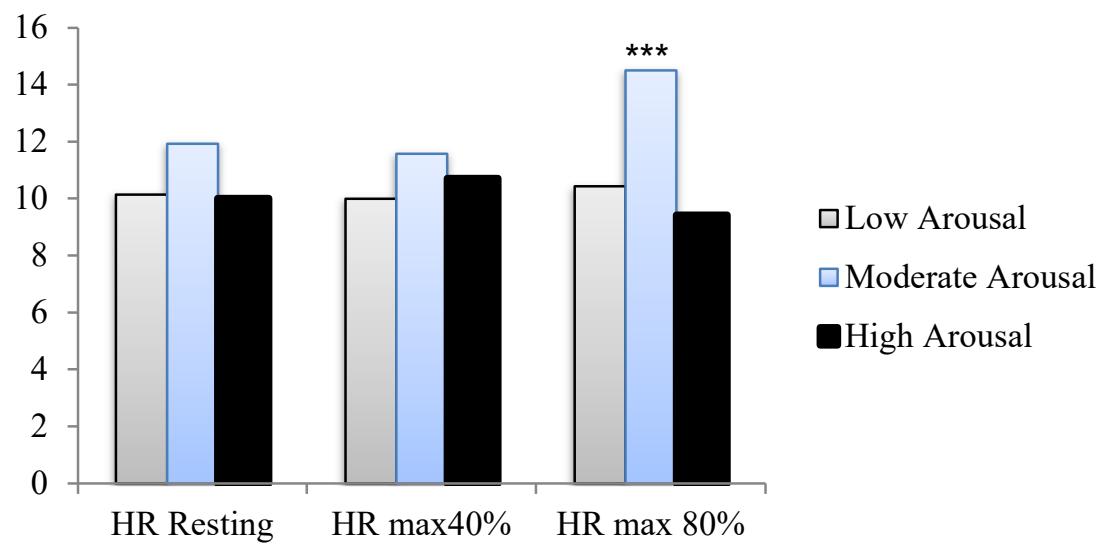

Figure 2. Block diagram displays the accuracy of decision making at different levels of exercise intensity and arousal. The sign *** shows a significant difference between the inactive spectator (moderate arousal) and the other two conditions (low and high arousal levels) at exercise intensity level of $80 \%$ HR max. $(\mathrm{p}<.001)$. Data displayed mean $\pm \mathrm{SD}$ and no. Of participants $=16$ 
The quickest decision making time at different levels of exercise level occurs at low arousal level (no spectators condition). There is no significant effect of arousal level on the speed of decision making at exercise intensity of 40\% HR max $(\mathrm{P}<$ 0.05). At $80 \%$ HR max the quickest decision making occurs at (low arousal) no spectators experiment.

Figure no. 2 shows a diagram of the accuracy of expert soccer players at different levels of intensity and arousal. The accuracy of decision making among expert soccer players is significantly improved at a moderate level of arousal (inactive spectators) as compared to other levels of arousal. There is no significant effect of level of exercise intensity at low (no spectators) and high (active spectators) levels of arousal ( $p<$ $0.05)$. Only at the moderate arousal level there was a significant difference in the accuracy of decision making $(\mathrm{p}<0.05)$.

At a moderate level of arousal (inactive spectators) there is a slight improvement in the accuracy of decision making at $40 \%$ HR max of exercise intensity however, this effect is not significant $(\mathrm{p}<0.05)$. In general we conclude that levels of arousal do not have a significant effect on decision making at different levels of exercise intensity (HR Resting and 40\% HR max). At 80\% HR MAX there was a significant effect of exercise intensity among different levels of arousal (no spectators, inactive spectators, active spectators) ( $\mathrm{P}$ $<0.05)$. At moderate arousal, the most accurate decision making occurs when the task is performed at high exercise intensity $(\mathrm{p}<0.05)$.

\section{Discussion}

The goal of the present study was to examine the effect of exercise intensity and arousal on the accuracy and decision making performance among expert female soccer players. According to the results of the present study, levels of arousal and exercise intensity have a significant effect on the accuracy and speed of decision making. At low arousal level, there is a significant improvement in the mentioned variables with increasing the level of exercise intensity $(\mathrm{P}<.05)$. A slight improvement in the accuracy of decision making at moderate arousal by increasing the level of exercise intensity however, this effect is significant only at the exercise intensity of $80 \% \mathrm{HR} \max (\mathrm{P}<.05)$. There was no significant effect of level of exercise intensity on the accuracy and the speed of decision making at high arousal level $(\mathrm{P}<.05)$.

The analysis performed on the data also revealed that the speed of decision making is at its lowest level at HR resting with no spectators (low arousal). There is not a significant effect of level of arousal on speed of decision making at $40 \% \mathrm{HR}$ max exercise intensity. At $80 \%$ HR max the most reduced speed of decision making occurs at no spectator (low arousal) condition. There is not a significant effect of level of arousal (no spectators, inactive spectators, active spectators) on the accuracy of decision making at any given exercise intensity $(\mathrm{P}<.05)$. At $80 \%$ HR max the most accurate decision making occurred at a moderate level of arousal (no spectators, inactive spectators, active spectators $)(\mathrm{P}<.05)$. 
In a study named exercise, catecholamine density of plasma(as the indicator of arousal) and decision making performance among soccer players McMorris and Myers (1999) compared college soccer players decision making performance in a soccer specific test in resting, threshold adrenaline and maximum power output levels. This study revealed that the fastest decision making performance among soccer players takes place at resting adrenaline levels. As mentioned in the results section of the present study at low and moderate arousal levels, the speed of decision making improves with increasing the levels of exercise intensity. The fastest decision making among the two mentioned arousal levels belong to resting situation The current results are in line with McMorris' results. In the other section of the results of this study it was revealed that there is no significant effect of increasing exercise intensity in the high arousal levels $(\mathrm{P}<0.05)$.

In another study on the effect of different exercise intensities on the novice and professional players' decision making by Fontana (2007) the results revealed that the decision making performance among the players of both groups increases at $60 \%$ and $80 \%$ exercise intensity. In other words the speed of decision making improves with increasing in the intensity of exercise among professional and novice athletes. These results are in line with the present study's findings which indicate that the speed of decision making improves with increasing the intensity of the exercise at low and moderate levels of arousal. The above mentioned results from Fonatana is however, is in contrary with the part of the present study that revealed there's no significant effect of exercise intensity on the speed of decision making at high level of arousal $(\mathrm{P}<0.05)$. McMorris and Greydon (1997b) suggest the increase in the speed of decision making at high levels of exercise intensity (increase in the arousal) is due to an increase in the recourses that are available to central nervous system. In the case of an effort accompanied by focusing on the task in high intensity exercise level, more resources will become available to the central nervous system as compared to the resting condition. The mere outcome of such experiment is nothing but a quicker response. Based on the allocation of the recourses, increase in the speed of decision making is anticipated at moderate exercise intensity as compared to resting condition. According to mcMorris and SteveMyers (1999) the lack of a significant effect of increase in exercise intensity level at a high level of arousal is explained to be associated with the ideal levels of Adrenaline production that prevents the latter variable from significantly affecting decision making. A significant improvement was observed in the speed of decision making with an increase in the exercise intensity from HR resting to $80 \% \mathrm{HR} \max (\mathrm{P}<$ 0.05). Considering soccer, the mentioned effect is extremely important. Increasing the ideal Adrenaline levels might be ineffective for this specific task. In other words, the quality of the task is capable of producing a floor effect suggesting that the increase in catecholamine is ideal only from resting to adrenaline threshold. Landers 
(1980) and Sanders (1983) suggested that increase in catecholamine is even capable of having negative effects on performance. The observed lack of increase in the speed of decision making in high levels of arousal could be interpreted that the exercise intensity is not accountable for making decision making quicker. The same exercise led to decrease in the speed of decision making at low and moderate levels of arousal. As it was stated in the results section, there is no significant effect of the level of exercise intensity on the speed of decision making. Landers (1980) indicate that similarity of the task leads to the sustaining of high level of arousal. Sanders (1980) also mentioned that individuals performing under stress automatically adjust their information processing strategies with these experiments. McMorris and Myers (1999) stated that professional players who are adapted to decision making at high levels of exercise intensity are not likely to be negatively affected by the mentioned variable in their performance. The present results are also explainable through the varieties of information processing. Assuming the expert groups' information processing is automatic or, the task is similar to one to which a response is produced previously; an increase in the level of arousal will not significantly affect the speed of decision making. Considering the quality of the task with the speed of decision making being at its ideal, the latter did not improve any further. In other words, high level of arousal provides access to adequate recourses and hence no changes are observed along with increasing the exercise intensity level.
In discussion and interpretation of investigation findings in the aspect of the accuracy of decision making it could be stated that when the individual is familiar with the task and there is an automatic component in the performance, fewer resources from the CNS are required for ideal performance. The explanation for the lack of significant difference in the accuracy of decision making from HR resting to $80 \%$ HR max is that; in a case that there are fewer than normal specialized resources available, making an effort at resting condition for instance, can specify enough resources for the task to be adequately accurate. The results of their study (McMorris \& Graydon, 1997b) provided supporting evidence for Iznack (1992) which suggests it is possible to specify resources to the task even under high levels of arousal. The ratio of increase in the Adrenaline and also its structure during exercise intensity is different in peripheral nervous system from the CNS. This fact explains the decision making at threshold levels of Adrenaline and the maximum power output is located at the peak of the inverted U. Lack of significant effect of level of exercise intensity in low arousal level.

According to Landers (1980), individuals are prone to sensitivity to nervous noises and scatteredness. This scatteredness is experienced to a lesser degree in moderate levels of arousal. Easterbrook, (1959) showed that attention is much outspread in low levels of arousal. In moderate levels of arousal however, specifying attention to related signs of the task are close. In high levels of arousal this closeness becomes more in such a way 
that might lead to missing some of the related signs. Scatteredness hence did not have any significant effect of the performance of expert soccer players for the mentioned reasons and the level of expertise. As Landers (1980) and Easterbrook (1959) mention, it is also suggested that moderate level of arousal produces different conditions compared to other levels of arousal for the players which led to observing a significant improvement in the accuracy of decision making at $80 \% \mathrm{HR}$ $\max$.

\section{Conclusions}

Investigating results of exercise intensity suggested that at resting HR participants had the slowest decision making with no spectators (low arousal). Manstead and Semin (1980) showed that automatic performance intends to deteriorate at lack of presence of the others. Their findings support what we obtained from the present study. The quickest decision making was associated with no spectators at exercise intensity of $80 \% \mathrm{HR}$ max. From mentioned conditions one can conclude that any further increase in arousal level leads after an increase in physiological arousal and reaching optimal level at inverted U (McMorris et al. 1999) leads to decrease in decision making. The quickest of reaction time takes place with no present spectators. As Cox (2000) work revealed any complex task which requires information processing will undergo deterioration under similar conditions mentioned above. In other words, such tasks require attention capacity at which high exercise intensity level and the presence of spectators will make an interfering effect on. Assessing the results obtained from the accuracy of decision making at different exercise intensity revealed that there is no significant effect of level of arousal at HR resting and $80 \%$ HR max. The most accurate decisions under $80 \%$ of exercise intensity were made at moderate arousal (with inactive spectators). There is no significant effect of level of arousal at exercise intensity levels of HR resting and 40\% HR max. The level of arousal revealed an effect similar to the inverted $\mathrm{U}$ at $80 \%$ exercise intensity. The most accurate and quickest decision making performance for players takes place at $80 \%$ HR max exercise intensity in conditions where the decision making practice is conducted with no spectators. The most accurate and quickest decision making performance at competition like conditions (presence of active spectators) takes place at $40 \%$ HR max.

\section{Practical Application}

Based on these findings, it is recommended to players to get familiar with conditions mentioned as important in this study at their practice sessions, so that they can perform at higher levels and make more accurate decisions in real competitions.

\section{References}

1. Schmidt, R. A., \& Wrisberg, C. A. (2008). Motor learning and performance: A situation-based learning approach. Human Kinetics.

2. Alain, C., \& Sarrazin, C. (1990). Study of decisionmaking in squash competition: a computer simulation approach. Canadian journal of sport sciences, 15(3), 193-200.

3. Andreas, H. (1996). Neuronale Ne tze als Hilfsmittel in ko mplexen Entscheidungsprozessen-Ein le rnfahiges Fuzzy-System zum Radfahren [Neural networks as a tool in complex decision processes. A learning fuzzy-system 
for bicyc ling]. Anwendungen der fuzzy-logik und neuronaler netze[Applications of fuzzy-logic and neural networks], 109-114.

4. Bard, C., \& Fleury, M. (1976). Analysis of visual search activity during sport problem situations. Journal of Human Movement Studies, 3(2), 14-222.

5. Campos, W. (1994). The effects of age and skill level on motor and cognitive components of soccer performance.

6. Crossman, E. R. F. W. (1959). A theory of the acquisition of speed-skill*. Ergonomics, 2(2), 153-166.

7. Cox, R. H. (1998). Sport psychology: Concepts and applications (No. Ed. 4). McGraw-Hill.

8. Dienstbier, R. A. (1989). Arousal and physiological toughness: implications for mental and physical health. Psychological review, 96(1), 84.

9. Easterbrook, J. A. (1959). The effect of emotion on cue utilization and the organization of behavior. Psychological review, 66(3), 183.

10.Eysenck, M. W. (2013). Anxiety: The cognitive perspective. Psychology Press.

11. Fontana, F. E. (2004). The Development of a Decision Making Instrument for Soccer (Doctoral dissertation, University of Pittsburgh).

12. Fontana, F. E. (2007). The effects of exercise intensity on decision making performance of experienced and inexperienced soccer players (Doctoral dissertation, University of Pittsburgh).

13. Gutnik, L. A., Hakimzada, A. F., Yoskowitz, N. A., \& Patel, V. L. (2006). The role of emotion in decisionmaking: A cognitive neuroeconomic approach towards understanding sexual risk behavior. Journal of biomedical informatics, 39(6), 720-736.

14. Landers, D. M. (1980). The arousal-performance relationship revisited. Research Quarterly for Exercise and Sport, 51(1), 77-90.

15. Lopes, J. E., Araújo, D., Peres, R., Davids, K., \& Barreiros, J. (2008). The dynamics of decision making in penalty kick situations in association football. The Open Sports Sciences Journal, 1(1), 24-30.

16. Karvonen, M. J. (1957). The effects of training on heart rate; a longitudinal study. Ann Med Exp Biol Fenn, 35, 307-315.

17. Karvonen, M.J., Kentala, E., \& Mustala, O. (1957). The effect of training heart rate: A longitudinal study. Annales Medicinae Experimentalis et Biologiae Fenniae, 35, 307-315.

18. Kioumourtzoglou, E., Kourtessis, T., Michalopoulou, M., \& Derri, V. (1998). Differences in several perceptual abilities between experts and novices in basketball, volleyball and water-polo. Perceptual and motor skills, 86(3), 899-912.

19. Kaufman, L., Kaufman, J. H., Noble, R., Edlund, S., Bai, S., \& King, T. (2006). Perceptual distance and the constancy of size and stereoscopic depth. Spatial vision, $19(5), 439-457$.

20.Mann, D. T., Williams, A. M., Ward, P., \& Janelle, C. M. (2007). Perceptual-cognitive expertise in sport: A meta-analysis. Journal of Sport and Exercise Psychology, 29(4), 457-478.

21. Marriott, J., Reilly, T., \& Miles, A. (1993). The effect of physiological stress on cognitive performance in a simulation of soccer. Science and football II, 261-264.

22. McMorris, T., \& Beazeley, A. (1997). Performance of experienced and inexperienced soccer players on soccer specific tests of recall, visual search and decisionmaking. Journal of Human Movement Studies, 33(1), 113.

23. McMorris, T., \& Graydon, J. (1996). The effect of exercise on the decision-making performance of experienced and inexperienced soccer players. Research quarterly for exercise and sport, 67(1), 109-114.

24. McMorris, T., \& Graydon, J. (1996). Effect of exercise on soccer decision-making tasks of differing complexities. Journal of Human Movement Studies, 30(4), 177-193.

25. McMorris, T., \& Graydon, J. (1997a). "The effect of exercise on cognitive performance in soccer-specific tests". Journal of Sports Sciences, 15, pp: 459-468.

26. McMorris, T., \& Graydon, J. (1997b).” Performance of soccer players on tests of field dependence/independence and soccer-specific decision-making tests". Perceptual and Motor Skills, 85, pp: 467-476.

27. McMorris, Terry, Myers, Steve, MacGillivary, William, SexSmith, James, Fallowfield, Joanne, Graydon, Jan, Forster, David (1999). "Exercise, plasma catecholamine concentrations and decision-making performance of soccer players on a soccer-specific test". Journal of Sports Sciences, 17, pp: 667-676.

28. McPherson, S. L. (1999). Expert-novice differences in performance skills and problem representations of youth and adults during tennis competition. Research Quarterly for Exercise and Sport, 70(3), 233-251.

29. Nielsen, T. M., \& McPherson, S. L. (2001). Response selection and execution skills of professionals and novices during singles tennis competition. Perceptual and motor skills, 93(2), 541-555.

30. Perl, J. (1997). "Moglichkeiten und Probleme der computerunterstu"tzendenInteraktionsanalyse am Beispiel Handball". [Possibilities and problems of computer-based analysis of interaction in handball] In J. Perl (Ed.), Sport undInformatik V: Berichtu"ber den 5. Workshop Sport und Informatikvom 17. bis 19. Juni 1996 in Berlin [Sports andComputer Science V. Proceedings of the Workshop of Sports and Computer Science 17th to 19th of June 1996 inBerlin], pp: 74-89.

31.Podolin, D.A., Munger, P.A. and Mazzeo, R.S. (1991).” Plasma catecholamine and lactate response during graded exercise with varied glycogen conditions. Jour nal of AppliedPhysiology, 71, pp: 1427-1433.

32. Raab, M. (2003). "Implicit and explicit learning of decision making in sports is effected bycomplexity of situation”. International Journal of Sport Psychology, 34, pp: 273-288.

33. Ripoll, H., Kerlizin, Y., Stein, J., \&Reine, B. (1995).” Analysis of information processing, decision making, and visual strategies in complex problem solving sport situations". Human Movement Science, 14, pp: 325-349. 
34. Roca, A., \& Williams, A. M. (2017). Does decision making transfer across similar and dissimilar sports? Psychology of Sport and Exercise, 31, 40-43

35. Saha, S., Saha, S., \& Zahir, N. E. B. M. (2014). Significance of Orienting Reflex on Emotional Resilience in Explaining High Performance in Soccer Players. International Medical Journal, 21(5), 459-462

36. Sanders, A.F. (1983). "Towards a model of stress and

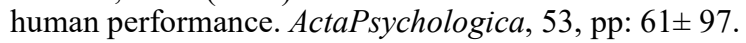

37. Sarrazin, C., Alain, C., \& Lacombe, D. (1986). "Simulation study of a decision-making model of squash competition, Phase two: testing the model through the use of computer simulation". Human Movement Science, 5, pp: 373-391.

38. Schmidt, R. A., \& Wrisberg, C. A. (2004). Motor learning and performance.

39. Stølen, T., Chamari, K., Castagna, C., \& Wisløff, U. (2005). Physiology of soccer. Sports medicine, 35(6), 501-536.

40.Tenenbaum, G., Yuval, R., Elbaz, G., Bar-Eli, M., \& Weinberg, R. (1993)." The relationship between cognitive characteristics and decision making". Canadian Journal of Applied Psychology, 18, pp: 48-62.

41. Davids, K., Williams, J. G., \& Williams, A. M. (2005). Visual perception and action in sport. Routledge.

42. Williams AM, Ford PR (2013) 'Game intelligence': anticipation and decision making. In: Williams AM (ed) Science and soccer III. Routledge, London, pp 105-121

43. Zoudji, B., \& Thon, B. (2003).” Expertise and implicit memory: differential repetitionpriming effects on decision-making in experienced and non-experienced soccerplayers". International Journal of Sport Psychology, 34(3), pp: 189-207.

44.Zoudji, B., Thon, B., Debu B. (2010).” Efficiency of the mnemonic system of expert soccer players under overload of the working memory in a simulated decisionmaking task". Psychology of Sport and Exercise, 11, pp: 18-26.

45. Yaaron, M., Tenenbaum, G., Zakay, D. \& Bar-Eli, M. (1997)." The relationship between age and level of skill and decision making in basketball". in: R. Lidor\& $M$. Bar-Eli (Eds) Innovationsin sport psychology. Linking theory and practice (Netanya, Wingate Institute for Physical Education and Sport), pp: 768-770. 